\title{
GOVERNANÇA (DISCIPLINAR) ALGORÍTMICA
}

\author{
Mariana Carolina Lemes ${ }^{1}$
}

RESUMO: A pesquisa qualitativa, de método indutivo, com uso da documentação indireta, visa responder como a análise de dados e metadados com papel preditivo de comportamentos vêm sendo utilizados pelas agências governamentais. A hipótese primária é de que os algoritmos devem ser utilizados com transparência e ética pelas agências governamentais. É objetivo geral do trabalho analisar os algoritmos como poderoso instrumento para a governabilidade. Os objetivos específicos voltam-se para a problematização dos riscos dos algoritmos opacos. Os Casos Wisconsin v. Loomis e SyRI foram discutidos, de forma a apontar os malefícios de códigos opacos no setor público.

Palavras-chave: Algoritmos tendenciosos; Controle; Exclusão; Infamiliar; Governança.

\section{(DISCIPLINARY) ALGORITHMIC GOVERNANCE}

ABSTRACT: Qualitative research, using inductive method and indirect documentation, aims to answer how data and metadata analysis with a predictive role of behaviors have been used by government agencies. The primary hypothesis is that the algorithms should be used transparently and ethically by government agencies. The general objective of the work is to analyze the algorithms as a powerful instrument of governability. The specific objectives focus on problematizing the risks of opaque algorithms. Wisconsin v. Loomis and SyRI cases were discussed, in order to point out the harm of opaque codes in the public sector.

Keywords: Biased algorithms; Control; Exclusion; Eerie; Governance.

\section{INTRODUÇÃO}

Os algoritmos guardam em sua genética as informações passadas por seus criadores e desenvolvedores. Esses códigos carregam consigo potencial para deflagrar situações discriminatórias, positivas ou negativas. Pesquisadores têm reportado em numerosos estudos os bons e maus usos dos algoritmos. De acordo com a primeira lei de Kranzberg, a tecnologia não é boa, ruim, nem, tampouco, neutra (KRANZBERG, 1995). Termos matemáticos como algoritmos e modelos vêm sendo utilizados, contudo, para encobrir realidades subjetivas (mathwashing) e, de acordo com O’Neil (2016), o impacto social causado pela majoração no

\footnotetext{
${ }^{1}$ Doutoranda em Direitos Fundamentais pela Universidade do Oeste de Santa Catarina - Unoesc. E-mail: mariana.lemes@ unoesc.edu.br. Orcid: https:orcid.org/0000-0002-4590-1107.
} 
uso de algoritmos e sua correlação com o aumento das desigualdades preexistentes justificaria denominá-los "armas de destruição em massa". Baseados na análise de dados do passado, os algoritmos tendem a repetir erros humanos e perpetuá-los através de loops de feedback. Sua acurácia é testada contra um marcador de referência que pode não ser representativo da população e dos valores culturais de uma determinada sociedade, de modo que sua precisão é relativa. Inobstante tantos problemas, a vigilância algorítmica tem se mostrado parte de uma tendência mundial na qual a análise de dados e metadados assume papel preditivo de comportamentos que podem deflagrar maior vigilância e controle sobre a pessoa, ou seja, os algoritmos vêm sendo utilizados como instrumentos de enfraquecimento das instituições democráticas.

Com a difusão de programas governamentais preditivos, inclusive securitários biopolíticos, cabe ao Direito interpretar seus diferentes usos e contextos, outorgando soluções jurídicas para os casos de conflito entre interesses político-econômicos estabelecidos verticalmente, em desfavor dos cidadãos. Reconhecendo que o problema existe e merece atenção da comunidade jurídica, precedentes como os Casos Wisconsin v. Loomin, nos Estados Unidos, e SyRI, na Holanda, foram recortados para oferecer contribuição voltada para o enfrentamento e diminuição de uma possível opressão político-algorítmica, oferecendo campo profícuo para o aprofundamento das pesquisas sobre algoritmos tendenciosos para responder como estes códigos invisíveis vêm sendo utilizados pelas agências governamentais para o controle político-social dos indivíduos. A hipótese primária apresentada é de que os algoritmos devem ser utilizados com transparência e ética pelas agências governamentais, reforçando a importância da accountability, pois podem ter seus códigos apropriados para a captação e armazenamento de dados e metadados dos usuários, cuja interpretação esteja voltada a elementos e características pessoais que permitam identificá-los como integrantes de grupos vulneráveis e minoritários, dificultando-lhes ou mesmo impedindo a fruição de direitos. São hipóteses secundárias: a captação e manipulação de dados pelos governosplataforma pode reproduzir o racismo-estrutural, devendo ser minimizado qualquer preconceito que esses códigos invisíveis possam carregar consigo; os algoritmos opacos ressaltam o infamiliar, motivo pelo qual podem ser utilizados como instrumentos de discriminação negativa e controle; sua utilização securitária, como proposto no Brasil, pode revelar que os algoritmos tendenciosos demonstram viés eugênico. 
A pesquisa possui justificativa social na difusão dos algoritmos tendenciosos e, consequente multiplicação dos casos de violação de direitos civis fundamentais e privacidade em todo o mundo. Sob uma perspectiva jurídica, o tema é recente, tendo sido as primeiras decisões ansiosamente aguardadas, diante do seu potencial perfil como precedentes para a solução de todos os casos similares, com a fixação de tese jurídica e análise da proporcionalidade da proteção deferível, a evitar a proteção deficiente e a excessiva. Finalmente, do ponto de vista científico, o estudo interdisciplinar se prevalece da psicanálise em sua busca para oferecer nova contribuição às discussões sobre tendenciosidade dos algoritmos.

O objetivo geral do trabalho é oferecer uma análise dos algoritmos como poderoso meio de realização da governança pelas agências governamentais. São objetivos específicos: apresentar e discutir o viés psicológico dos algoritmos (efeito de "ancoragem"); a noção de infamiliar (das Unheimliche) explorada pelos algoritmos; correlacionar o estranho-familiar e o mau uso dos algoritmos opacos, em especial pelos Estados-nação; discutir a aceitação jurídica da nova vigilância algorítmica atualidade.

A pesquisa, qualitativa, segue o método de indutivo, com uso da documentação indireta. Foi organizada em duas seções, destinando-se a primeira delas à nova política de vigilância e controle governamental exercidos em ambiente digital, com a análise de programas como amostragem em a segunda seção dedica-se à discussão do infamiliar, com matriz teórica no pensamento freudiano, problematizando a exclusão e, a inclusão da exclusão, reafirmando a importância de uma governança com forte senso de responsabilidade e ética, comprometida com a transparência no uso dos algoritmos.

\section{NOVA VIGILÂNCIA ALGORÍTMICA}

Prevalecendo-se de algoritmos opacos, Estados-nação têm utilizado as novas tecnologias como meio de exercício da surveillance (vigilância-segurança-manipulação de dados e metadados), tornando o controle exercido sobre o corpo dos indivíduos ainda mais invisível e difuso.

O termo surveillance possui densidade e complexidade. Os modelos panópticos - de vigilância do indivíduo - já não podem ser comparados à forma hiperconectada como ocorrem o vigiar e controlar pós-panóptico. A globalização e os limites transfronteiriços dos 
movimentos globais geram inseguranças e, a coleta de informações sobre os indivíduos tornase uma estratégia de controle social preditivo, cujo objetivo é reforçar o poder do Estado, denominado new surveillance. Esse banóptico opera de forma descentralizada, permeando as relações sociais com a biopolítica (BAUMAN, 2014, BIGO, 2006, MORAIS, 2018, THIESEN; SANTANA, 2008). O conhecimento algorítmico funcional-utilitarista acumulado por Estados, corporações e agências, aliado à concentração, sistematicidade e rotina de sua produção "normalizada" mostram-se, cada vez mais, arraigados na governança, estando impregnadas de questões econômicas e jurídicas (MORAIS, 2018, MENEZES NETO, 2014), criando uma nova anatomia do poder (THIESEN; SANTANA, 2008). Essa dataveillance permite, sob o argumento de proteção do mercado, a opacidade dos algoritmos, legitimando a lesão massiva a direitos individuais, de modo que os dados dos usuários transformaram-se em campo de exploração do capitalismo parasitário (BAUMAN, 2010) de plataforma, nova fase do capitalismo, na qual a exploração econômica de dados e metadados ocupa centralidade (SRNICEK, 2017).

Para Srnicek, o poder de agência responsável pela passagem da economia para esta nova fase se deve às grandes empresas de tecnologia. As plataformas atuam como intermediárias - verdadeiras organizadoras de mercados - oferecendo infraestrutura básica para a mediação de diferentes grupos; quanto maior o número de usuários, maior o seu valor intrínseco e extrínseco, com uma tendência à monopolização. A monetização dos serviços oferecidos é enganosamente transportada para outros ramos da plataforma. Mais e mais usuários são atraídos em razão da não monetização dos serviços fornecidos, mas se esquecem de que os custos de sua oferta são compensados. Ou seja, depois de organizar os mercados aos quais se dedicam, as plataformas - de propaganda, de nuvem, de indústrias, de produtos ou enxutas - atuam sobre o formato do mercado, definindo regras de interação, geração de valor e distribuição deste em seu ecossistema (SRNICEK, 2017).

\subsection{NOVA POLÍtICA DE VIGILÂNCIA E CONTROLE GOVERNAMENTAL NO ECOSSISTEMA DIGITAL}

Os governos têm aderido com mais e maior frequência à coleta e manipulação de dados obtidos através de suas plataformas para implementar a vigilância pelos números. Essa nova forma securitária utiliza os modelos de computador e algoritmos tendenciosos para, 
através de agências governamentais, realizar a análise preditiva de crimes a partir da análise de dados que refletem o comportamento individual. Denominados "avaliadores de risco", esses softwares podem ser utilizados para identificar os tipos de supervisão necessárias para cada preso, o tipo mais apropriado de encarceramento, a probabilidade de recidiva no caso de liberação mediante fiança ou liberdade condicional, ou, ainda, como parte do processo de julgamento criminal, como ocorre nos Estados Unidos. Nesses casos, a rede neural de dados funciona como uma caixa preta que permite o acesso às informações de entrada e de saída, mas, que não permite compreender o processo entre esses pontos, o que torna difícil identificar e depurar erros (ANGWIN et.al., 2016, CORBET-DAVIES et. al., 2016, TASHEA, 2017).

As agências governamentais costumam adquirir seus algoritmos de empresas privadas. A falta de transparência e de regulação dos algoritmos impede que se identifique o processo real de tomada de decisões, sendo este do conhecimento apenas dos seus criadores e, em alguma medida, de seus adquirentes.

A utilização de algoritmos opacos pode, porém, impactar frontalmente os direitos individuais e abalar as noções de Estado de Direito. Tal afirmativa pode ser evidenciada por casos notórios como Wisconsin v. Loomis. Eric Loomis foi encontrado em fevereiro de 2013, dirigindo um veículo utilizado em um tiroteio. Preso, Loomis respondeu um questionário com 137 itens, desenvolvido pela empresa Equivant (anteriormente Northpoint) e comercializado com o nome COMPAS para os estados americanos de Nova York, Wisconsin, Califórnia, e, na Flórida, para o Condado de Broward, entre outras jurisdições. Tendo sido classificado com alto risco de reincidência, Loomis foi condenado. A defesa apresentou apelo baseado em duas premissas: (1) em razão do uso de código-fonte fechado, protegido por segredo comercial, para avaliação de risco, teria ocorrido violação do direito do acusado ao devido processo legal, já que a opacidade do algoritmo empregado impedia a contestação de sua validade científica e a exatidão; e, (2) o racismo e sexismo da ferramenta, que leva em consideração gênero e raça. O julgamento do apelo foi recusado em junho de 2017. A Suprema Corte do Estado de Wisconsin entendeu que a utilização de avaliação de risco algorítmica não violou os direitos do acusado ao devido processo legal, ainda que a metodologia utilizada para produzi-lo não seja transparente nem para a Corte nem para o sentenciado. A Corte entendeu que a existência de avisos escritos sobre os perigos destas avaliações seriam suficientes. A primeira advertência é sobre direitos de propriedade sobre o programa, os quais impedem a 
divulgação de como as pontuações de risco são calculadas. A segunda esclarece que as pontuações são incapazes de identificar indivíduos de alto risco específicos, dada a necessidade de dados de grupo. A terceira anota que o COMPAS é baseado numa amostragem nacional, não tendo sido realizados estudos de validação cruzada para a população específica do Estado ou Condado que o utiliza. A quarta advertência estabelece que infratores minoritários podem ser pontuados desproporcionalmente como tendo um risco maior de reincidência e, a quinta, que a ferramenta foi criada para auxiliar o Departamento de Correções a fazer determinações pós-sentenciamento. O tribunal justificou que as pontuações de risco não podem ser usadas para determinar se alguém será preso ou a gravidade da sentença, devendo o juiz prolator da decisão explicar os diferentes fatores levados em consideração para apoiar a sentença imposta (STATE, 2017).

Revisão elaborada pela Harvard contrapõe, porém, que a recomendação não criaria ceticismo judicial significativo ao silenciar sobre as críticas e desconsiderar as pressões internas e externas sobre os juízes para a sua utilização e, que as críticas às avaliações de risco algorítmicas são muito maiores, expressando cautela particular quanto ao uso da tecnologia em contextos que possam reforçar desigualdades já existentes, disfarçando discriminação aberta com base em dados demográficos e status socioeconômico. Ademais, testes independentes da ferramenta COMPAS mostraram a maior propensão à classificação de risco mais alta para infratores afrodescendentes, em comparação com infratores brancos (STATE, 2017, HOLDER JR., 2015). Após ter sido tachado de tendencioso contra os negros pela organização de notícias investigativas ProPublica, a empresa, então denominada Northpoint, lançou um relatório questionando a análise, levando a Suprema Corte de Wisconsin a citar a controvérsia após pesquisadores acadêmicos da Universidade do Estado da Califórnia terem ingressado na discussão (CORBET-DAVIES et. al., 2016).

Foi possível concluir que, a atribuição de pontuações pelo COMPAS variava de 1 a 10, indicando sua maior ou menor probabilidade de reincidência. Eram considerados 100 fatores, aí incluídos idade, sexo e história criminal, mas não a raça. Dados de cerca de 5.000 casos de Broward County, Flórida, obtidos pela ProPublica foram analisados. Os réus com alta pontuação de risco reincidiram quase 4 vezes mais que aqueles de pontuação baixa ( $81 \%$ do primeiro grupo e, $22 \%$ do segundo). Entre os réus com pontuação 7, $60 \%$ dos réus brancos reincidiram e, $61 \%$ dos réus afrodescendentes, argumento utilizado pela Northpoint em favor da justeza do algoritmo. Entre os réus que não reincidiram, os afrodescendentes tinham 2 
vezes mais chance de serem taxados como médio ou alto risco que os brancos, ainda quando não tivessem cometido um crime, estando, ainda, sujeitos a tratamento mais rigoroso por parte dos tribunais. $\mathrm{O}$ fato de o algoritmo cometer erros com maior frequência em desfavor dos afrodescendentes demonstraria, segundo a ProPublica, a tendência de injustiça do mesmo. Quatro pontos restaram estabelecidos no estudo: (a) dentro de cada categoria de risco, a proporção de réus que reincidiram é aproximadamente a mesma, independentemente da raça; (b) a taxa geral de reincidência para réus negros é maior do que para réus brancos (52\% contra 39\%); (c) os réus negros têm maior probabilidade de serem classificados como de médio ou alto risco (58\% contra 33\%), pois embora o algoritmo não use raça diretamente, muitos atributos que prevêem reincidência variam de acordo com a raça (exemplificativamente: réus negros são mais propensos a ter prisões anteriores e, como prisões anteriores preveem reincidência, o algoritmo sinaliza mais réus negros como de alto risco; e, (d) réus negros que não reincidam oferecem maior risco do que réus brancos que não reincidem. De posse destes pontos-chave, observou-se que, dadas as afirmações dos dois primeiros pontos, os últimos 2 são garantidos, de modo que o desequilíbrio denunciado pela ProPublica sempre ocorrerá. Mais: o COMPAS foi projetado como uma medida de segurança pública e, em razão do policiamento mais pesado em bairros predominantemente negros, ou preconceito na decisão de fazer uma prisão, os negros podem ser presos com mais frequência do que os brancos que cometem o mesmo crime (CORBET-DAVIES et. al., 2016).

A Northpoint se recusou a divulgar os detalhes do seu algoritmo, impossibilitando avaliar completamente até que ponto poderia ser tendencioso. Corbett-Davies et. al. (2016) defendem que a solução não seria o abandono dos algoritmos preditivos, mas, sim, o estudo de soluções. Sugerem que aumentar a pontuação dos brancos seria igualmente arriscado, recomendando sejam estudadas mudanças que possam corrigir os desvios matemáticos (FLORES; LOWENKAMP; BECHTEL, 2017).

A discussão sobre os critérios de justiça para diferentes grupos, utilizados no Caso Wisconsin v. Loomin, foi objeto de pesquisa de Kleinberg, Mullainathan e Raghavan (2016). Segundo eles, três condições de justiça estariam no centro do debate e, exceto em casos especiais altamente restritos, não há método que possa satisfazê-las simultaneamente. Outrossim, mesmo que fosse possível satisfazer todas as três condições, os dados devem representar uma versão aproximada de um dos casos especiais identificados, sugerindo que 
algumas das maneiras pelas quais as noções-chave de justiça são incompatíveis umas com as outras, de modo que devem ser pensadas estruturas para compensações entre elas.

Outro exemplo da utilização de algoritmos tendenciosos é o Caso "SyRI". A Corte Distrital de Haia, na Holanda, decidiu que um algoritmo secreto, implantado em 2014 pelo Ministério das Relações Sociais, e, utilizado em bairros de baixa renda e de imigrantes nas cidades de Roterdã, Eindhoven, Capelle aan den Ijssek, e Haarlem, para apontar indivíduos com maior tendência ao cometimento de fraudes, viola os direitos humanos e as regras de privacidade. A decisão adotada no Caso SyRI pode influenciar o modo como outros países e cortes se posicionarão diante de outros casos envolvendo algoritmos preditivos em contextos políticos. O programa SyRI (System Risk Indicator) processava quantidades expressivas de dados pessoais armazenados em agências governamentais utilizando um algoritmo opaco, o que poderia, inadvertidamente, gerar conexões tendenciosas (BURACK, 2020, DUTCH, 2020). Através do algoritmo preditivo e de uma prévia assinalação de pontos, o sistema programado para coletar 17 categorias de dados governamentais, como histórico de tributos, registro de imóveis e de veículos - tinha o objetivo de calcular riscos individuais e beneficiar agências. A Corte entendeu que: o Regulamento Geral de Proteção de Dados proíbe a coleta de dados pessoais nessa escala; predeterminar que qualquer pessoa vivendo em determinada área como sendo mais tendente a cometer um crime constitui violação de direitos humanos. $\mathrm{O}$ governo holandês havia defendido a utilização do programa sob os argumentos de que o mesmo não enseja, necessariamente, consequências legais ou administrativas para os indivíduos identificados como de alto risco para o cometimento de fraudes. Contudo, a intenção por trás da coleta massiva de dados e o poder assimétrico entre o governo e seus habitantes de baixa renda, com a realização de uma vigilância em massa, foram considerados suficientes pela Corte.

Na contramão desta tendência, a China vem implantando nos últimos anos um sistema de crédito social baseado nas atividades de seus cidadãos, permitindo-lhes maior acesso a produtos e serviços - desde os básicos - aos melhor pontuados. A iniciativa governamental, anunciada em 2014, tem a intenção de obter um acesso holístico, baseado em um score numérico. As consequências de uma pontuação baixa podem ser sérias, afetando perspectivas de viagens, emprego, acesso a recursos financeiros e a habilidade de celebrar contratos. O sistema unifica dados individuais, de empresas e governamentais. Conquanto o 
sistema ainda seja voluntário, há pressão para a adesão e ele deve se tornar mandatório no futuro (DONNELLY, 2021).

No Brasil, Lemes (2019) procurou verificar de que maneira o poder público brasileiro se situa em relação às iniciativas algorítmicas e de inteligência artificial (IA). A pesquisa exploratória, realizada a partir do levantamento de dados nos endereços eletrônicos dos Ministérios e de órgãos públicos, utilizou argumentos booleanos (admitem apenas dois valores) nas ferramentas de pesquisa do Google. A falta de um registro oficial e central dos sistemas implementados teria impedido a realização de uma exploração rigorosamente quantitativa e, diante do número elevado de iniciativas mapeadas, os esforços foram concentrados no projeto Sinesp Big Data e Inteligência Artificial para Segurança Pública, desenvolvido pelo Ministério da Justiça e Segurança Pública (MJSP) em parceria com o Departamento de Computação da Universidade Federal do Ceará (UFC), vinculado à Lei 13.675, a Lei do Sistema Único de Segurança Pública (BRASIL, 2018) e aos sistemas de inteligência policial implementados pelo Governo do Ceará, para a prática de policiamento preditivo, com o encaminhamento de comunicações eletrônicas e solicitações de acesso à informação. A pesquisadora apontou as respostas vagas aos questionamentos formulados, bem como negativa de contribuição em face de acordos de confidencialidade e, concluiu pelo forte traço disciplinar do Sinesp Big Data, entendendo que ele é exemplo de governança disciplinar de indivíduos de risco, com prováveis efeitos discriminatórios.

Outros exemplos de decisões baseadas em algoritmos podem ser encontradas na cidade de Nova York, que os utiliza para a seleção de edifícios a serem inspecionados quanto ao risco de incêndio, tomando como base dados de incêndios anteriores e características da construção. Ela também utiliza dados de viagens de táxi para decidir como regulamentar ou alugar veículos e, dados de mapeamento para informar aos socorristas rotas mais rápidas para atender uma emergência. Na cidade de Chicago, para identificar crianças em risco de envenenamento por chumbo. A polícia da Filadélfia também se prevaleceu da análise dos dados para lançar um programa de "diversão" para jovens, no qual os alunos são frequentemente colocados em programas pós-escola em vez de prisões por certos crimes de baixa gravidade, reduzindo, no primeiro ano, as prisões de estudantes caíram pela metade. Uma colaboração multiagência, o GovLabPHL, emprega dados do comportamento humano para moldar como a cidade interage com os residentes, como, por exemplo, através do mapeamento dos pontos críticos de lixo, de modo a estimular a limpeza. Na Filadélfia, Nova 
York, Cambridge e Massachusetts, os sites de dados abertos das cidades convidam o público a examinar as informações e os métodos das cidades para interpretá-las, tornando o processo mais transparente. Em 2018, Nova York reuniu uma força-tarefa para estudar como a cidade usa os dados, propondo a redação de recomendações sobre como a cidade deve avaliar sua tomada de decisão automatizada, de modo a garantir equidade e oportunidade. O centro de pesquisa AI Now Institute da New York University estuda implicações sociais da inteligência artificial, escrevendo e atualizando códigos de conduta, inclusive princípios comunitários sobre práticas éticas, compartilhando métodos de processamento de dados e divulgando preconceitos injustos em algoritmos, de forma a que sejam reconhecidos e mitigados (BOND, 2018).

As experiências governamentais coletadas, colocam à mostra que, além das pressões internas e externas de um sistema que estimula o uso de avaliações quantitativas - o que por si só já demonstraria os riscos envolvidos na utilização de algoritmos preditivos --, existem vieses psicológicos que encorajam o uso de ferramentas de avaliação de risco na tomada de decisões. Os indivíduos tendem a pesar as avaliações empíricas supostamente especializadas mais fortemente do que as evidências não empíricas, o que pode criar um viés a favor das avaliações, em detrimento da própria narrativa fática posta em análise, sugerindo que é desafiador e incomum para os indivíduos desafiar as recomendações algorítmicas, fenômeno designado "ancoragem" pelos economistas (STATE, 2017).

\subsection{AMPLIFICAÇÃO ALGORÍTMICA DO INFAMILIAR E GOVERNANÇA}

Com a difusão das novas tecnologias e do mau uso de algoritmos tendenciosos, as injustiças e desigualdades já existentes parecem se tornar hipervisíveis. Apropriadas pelos governos, as ferramentas algorítmicas têm o potencial de reproduzir o racismo estrutural já existente, e estimular o seu crescimento.

A questão é tormentosa e vêm recebendo a atenção da academia.

Em Cambridge, o Open Data Review Board, recomenda políticas para governar conjuntos de dados abertos da cidade. Sua criação estabeleceu uma importante fonte de accountability e a possibilidade de novos investimentos na cidade. Os dados têm o propósito de aconselhamento da Administração em políticas e procedimentos. Uma equipe, composta por 1 representante da comunidade, 1 representante do Departamento de Tecnologia da 
Informação, 1 representante do Departamento de Comunicações Emergenciais e, 1 do Gabinete da Administração Municipal, além de 4 residentes, representando a academia, a comunidade empreendedora e de tecnologia civil são responsáveis pela revisão do quadro aberto de dados. A Universidade de Cambridge também é responsável por uma publicação, voltada a ajudar a cidade a identificar novas formas de engajar trabalhadores e residentes em torno dos dados abertos e, tem o objetivo de se transformar, de um programa de dados abertos para um programa de análises e dados abertos. Cambridge também vem colocando em prática parcerias com cidades como Boston, para a difusão de dados abertos (OPEN, 2019).

Pesquisadores da Johns Hopkins e de San Francisco, Data Community DC e DataSmart City Solutions da Harvard University disponibilizaram ferramentas que orientam as pessoas nas questões a serem consideradas para minimizar os riscos éticos ("Ethics and Algorithms Toolkit"), além de softwares que as cidades podem usar para auditar seus dados em busca de vieses (ETHICS, [s.d.]).

As preocupações éticas evidenciadas vêm sendo enfrentadas através da transparência e da estrutura de accountability no setor público, onde o uso de ferramentas algorítmicas vem oferecendo oportunidades e inovação.

A IA vem se movimentando para o centro da governação administrativa e, o Direito Administrativo está mal equipado para o desafio de mediar as colisões entre tecnologia e Estado-Administração (ENGSTROM; HO, [s.d.]). Uma abordagem de governança completa pode se privilegiar da compreensão do modo como se relaciona a população, inclusive as repercussões de fenômenos contemporâneos, como a migração e seu impacto cultural, desemprego, miséria etc., pelo que se propõe uma análise psicanalítica do infamiliar, também denominado o estranho-familiar, a partir do pensamento de Sigmund Freud.

Das Unheimliche seria palavra-conceito, expressão daquilo que aterroriza, que suscita angústia e horror. Sem tradução precisa para o português, das Unheimliche é adjetivoadverbial comum na língua alemã, mas ganhou força de estatuto conceitual na psicanálise a partir de 1919, data da publicação do ensaio. O conceito trouxe novo significado e emprego para a palavra Unheimliche, a rigor intraduzível. Pode-se encontrar, ainda, a referência ao "inquietante-estranho", "inquietante-estranheza", "inquietante familiar", "inquietante", "o sinistro", “o ominoso", "o perturbante", “o estranho". Suas diversas traduções denotam a impossibilidade enfrentada pelos tradutores de carregar, para outra língua, todo o sentido impresso em das Unheimliche. 
O infamiliar ressoa e reverbera no íntimo, evocando um conhecimento esquecido, oculto. Essa familiaridade perdida atua como vínculo corrompido, causando estranhamento e aversão, inquietação diante do que já não se reconhece. A angústia relativa ao enfrentamento de um desconhecer algo antes conhecido, a um afastar algo antes próximo, à "desfamiliarização" do outrora familiar. É esse "não querer reconhecer aquilo que deve ficar escondido do consciente" a inquietação que se quer traduzir e que, doravante, será tratada apenas como o "infamiliar".

A estética, destacou Freud, é o domínio do infamiliar, mas, preocupada, de modo geral, com sentimentos positivos como o belo, o grandioso e o atrativo, os estéticos negligenciaram sentimentos negativos, como o repugnante, o penoso, e, o infamiliar. Com o espeque de investigar o infamiliar, Freud fez opção por dois caminhos metodológicos, analisando, de um turno, o seu desenvolvimento léxico, e, de outro, as impressões sensíveis, vivências e situações despertadas pelo infamiliar. O fez com o intuito de, identificando os pontos comuns a ambos os procedimentos, desvendar como algo íntimo, desde há muito conhecido, pode se tornar algo aterrorizante.

A aversão pelo infamiliar é marca das sociedades humanas, derivada da impossibilidade de constituir o Eu sem destruir a ameaça que representa o outro. A perda da semelhança acena como ameaça à manutenção de quem se é e o que esse Eu representa na sociedade; o infamiliar detona o medo à perda da identidade pessoal e social.

Embora algumas vezes o estranho possa ser amado e admirado, a aparição de um outro ser, suficientemente semelhante, mas diferente provoca, modo geral, uma resposta particular que se expressa através do desprezo e do estranhamento, do repúdio àquilo que se reputa diferente. O não-familiar desperta o sentimento de não-pertencimento, do ser alheio, bárbaro, ou indesejável. Tal é o problema da alteridade: a diferença desperta desconfiança e agressividade. Situações antes tidas como certas passam a ser objeto de questionamento, alterando o status quo e gerando um quadro de instabilidade, de insegurança. Diante do confronto com o outro, um primeiro juízo, de valor, de eixo axiológico, o categoriza como bom ou mau, digno do amor ou do ódio, de ser reconhecido como igual ou como inferior. Numa perspectiva praxeológica, o encontro com o semelhante-estranho traz consigo o prognóstico de um embate, sendo a submissão o resultado caso a subjugação do outro não ocorra; a afirmação da superioridade dos valores próprios implica a confirmação da inferioridade dos do outro. Superados os eixos axiológico e praxeológico é que, numa 
operação epistemológica de conhecer e reconhecer a alteridade, é possível reconhecer a alteridade (CEREIJIDO, 2008).

Sob um olhar individual, o Eu é cego quanto a si mesmo. É através do olhar do outro sobre si que se propõe a conhecer mais sobre si próprio. Socialmente, o narcisismo é substituído pelos preconceitos, representando estes a parte inconsciente da ideologia de dada sociedade; seus sentimentos, juízos e atitudes. São os preconceitos que provocam e justificam a discriminação, a separação, a segregação e a exploração do outro.

Entender que determinado país, raça, religião ou ideologia seja melhor ou mais correto é, exemplificativamente, uma postura etnocêntrica. Este referencial autocentrado é mais perceptível através do [método do] distanciamento, que permite maior lucidez em relação à realidade. Os costumes e as justificações banalizam as circunstâncias cotidianas e as fazem escapar a um exame crítico, de modo que o familiar se torna de difícil percepção crítica.

O semelhante-familiar, de outro lado, está alinhado com a realidade em que está inserido o $\mathrm{Eu}$. O reconhecimento desta semelhança permite a convivência harmônica, fruto da ausência de estimulação do espaço cultural como estressor. O semelhante-infamiliar, ao contrário, provoca reação ambiental, ao abalar o estabelecido. Os preconceitos racial, social, cultural e religioso são problemas difusos, de matriz econômica, política e sociológica, objeto de atenção da psicologia social. Pode-se verificar a menção, ainda, ao fato do preconceito vincular-se, também, à personalidade autoritária, rígida, eis que ela se ressente da falta de capacidade para a re-adaptação à evolução das estruturas sociais. O sujeito com personalidade democrática, em compensação, seria mais flexível e tolerante (CEREIJIDO, 2008).

Nas sociedades, a supressão de direitos, de modo a diminuir - ou mesmo extinguir - a possibilidade de que o indivíduo infamiliar seja reconhecido, formal e materialmente, como seu titular, é elemento totalitário, verdadeira violência que se traduz num primeiro passo para a dominação e eliminação do diferente. A este primeiro degrau se segue a eliminação de sua condição de suficientemente semelhante, de ser humano, destruindo a solidariedade da comunidade a que pertence para, ao fim, alcançar a anomia e não reconhecimento de si mesmo como sujeito de direito frente aos dominadores, assassinando-se a individualidade, até que a massa amorfa e atomizada se torne supérflua, verdadeiro refugo humano.

Percebe-se, pois, que o repúdio ao estranho-familiar abrange o psiquismo individual e o imaginário social. 
Os estrangeiros e, em especial, os imigrantes, o negro, o não-heterossexual, o pobre, todos eles têm um traço comum; representam o que não se quer ser. Traduzem-se na negação daquilo que se reconhece como uma vida significativa. Nega-se o isolamento cultural, racional, religioso, sexual e social em desconformidade com o culturalmente aceito e, ao deparar-se com a familiaridade que se buscou suprimir, condena-se a representação daquilo que se nega.

A negação das semelhanças com os grupos acima citados revoga uma das etapas de recalcamento, expressando aquilo que pretende-se reprimir no Eu: aquele algo familiar inconfessável e secreto, que deve permanecer encoberto. Nega-se a semelhança e, mediante tal negação, professa-se a diferença com o infamiliar. O infamiliar se torna infausto objeto de condenação e, no caso dos grupos minoritários citados, párias.

Dentre os párias, uma ínfima minoria logra a ascensão, abandonando sua posição de inferioridade para ser elevado em sua glória, empersonando viva representação do mito do herói. Mesmo o imigrante, o negro e o homossexual podem ser aceitos, desde que lhes acuda a beleza, a riqueza ou outra atração estética (o sucesso, por exemplo), evitando, assim, a experiência estética desfavorável e, consequentemente a infamiliaridade e suas consequências.

$\mathrm{Na}$ sociedade do controle e da hipervisibilidade, o infamiliar pode ser exponencialmente estimulado, colocado em evidência, podendo ser manipulado com intuito eugênico, especialmente nos cenários da segurança pública.

As diferenças sociais, raciais, de gênero e etárias podem ser exacerbadas pelas agências governamentais de modo sub-reptício, validando o infamiliar e promovendo a reinserção do conceito de inimigo de Schmitt (1992).

A reintrodução do conceito de inimigo tem sido figura central na política nos últimos anos, colocando em evidência a tendência atual de inflação da segurança pública. A justificação de países como os Estados Unidos e seus aliados, sobre a necessidade de globalizar a segurança tem alcançado intensidade e alcance sem precedentes.

De Genova (2013) produz interessante argumentação acerca dos interesses por trás da exclusão, afirmando que torná-la visível alimenta a controvérsia antagônica (exemplificativamente, as manifestações anti-imigrantes no caso de visibilidade da ilegalidade do migrante), promovendo a inclusão dos sujeitos-alvo excluídos através da devoção à subordinação do trabalho, assegurando, assim, uma forma de subjugação. Esse processo sociopolítico (e legal) de inclusão por meio da exclusão, é concebido por De Genova como o 
“obsceno da exclusão", servindo como justificativa para essencializar as desigualdades de cidadania como diferenças categóricas que então podem ser racializadas.

Se os últimos 30 anos testemunharam o crescimento da hoje vasta literatura sobre governança, as transformações e incertezas do mundo globalizado e da tecnologia não se prestam a justificar lesões a direitos fundamentais civis.

A IA pode prestar valioso auxílio para a solução de problemas complexos do setor público e, um número crescente de agências governamentais têm considerado ou já adotaram os processos de decisão baseados em algoritmos preditivos. A pandemia veio ao encontro deste movimento, acelerando a velocidade deste fenômeno.

Seja para a identificação de evasões fiscais, análise de dados de saúde e serviços sociais e priorização do bem-estar de crianças, ou, ainda, para prever a taxa de contaminação por doenças infecto-contagiosas, os governos são chamados a atuar de forma mais eficiente, melhorando os resultados oferecidos e, mantendo os gastos em patamares reduzidos. A pressão para que os governos exerçam melhor sua função torna premente a utilização de algoritmos, mas demanda a checagem consciente dos desvios apresentados. Além de estáveis, devem ser transparentes, especialmente no setor público, vez que os administradores devem atuar dentro da mais estrita legalidade (DHASARATHY; JAIN; KHAN, 2020).

Nestes novos tempos, a governança deve possuir forte senso de responsabilidade e ética. A transparência no uso dos algoritmos e a promoção do engajamento da comunidade deve ser um compromisso das Administrações nesta nova fase, de modo a evitar lesões a direitos fundamentais e observar a legalidade, extraindo o melhor proveito possível da disciplina e da vigilância às quais os cidadãos se tornam cada dia mais expostos. Compete, ainda, especialmente à Academia, continuar as pesquisas sobre o tema em todas as áreas competentes, refutando o uso de códigos opacos e, empregando sua atenção para a solução de desvios tendenciosos.

\section{CONCLUSÃO}

Ao final deste estudo, espera-se ter demonstrado o potencial benéfico e danoso dos algoritmos tendenciosos para a governança. A utilização de programas com algoritmos opacos pode, comprovadamente, mascarar intenções e propósitos discriminatórios, inclusive quando utilizados pelos Estados-nação e Administradores Públicos. 
O modo como os algoritmos vêm sendo utilizados pelas agências governamentais para o controle político-social dos indivíduos, captando e armazenando dados e metadados para, após, valorá-los utilizando elementos e características pessoais através de códigos opacos, que permitem dificultar ou impedir a fruição de direitos, como ocorreu no Caso SyRI, deve ser repudiada. A utilização dos algoritmos, inclusive pelas agências governamentais, deve ser pautada pela responsabilidade e transparência.

O Caso Wisconsin v. Loomis aponta como a governança disciplinar pode reproduzir o racismo-estrutural, uma vez que os algoritmos opacos ressaltam o infamiliar e, vêm sendo utilizados como instrumentos tendenciosos, de discriminação negativa e controle de grupos vulneráveis, inclusive para a subjugação destes.

O ranking social chinês e o programa securitário brasileiro Sinesp Big Data e Inteligência Artificial para Segurança Pública confirmam a tendência de multiplicação dos casos de violação de direitos civis fundamentais e privacidade em todo o mundo, reforçando a importância da decisão exarada no Caso $S y R I$ e as diversas contribuições acadêmicas que vêm afluindo e que permitem a melhor compreensão do tema e capacitação dos governantes e dos cidadãos.

Certamente, novas demandas sobre a vigilância estatal surgirão, mas a accountability mostra-se, atualmente, como o melhor e mais poderoso instrumental para o enfrentamento do fenômeno. Com responsabilidade e ética, forte compromisso com a transparência no uso dos algoritmos e promoção do engajamento da comunidade, especialmente da academia, poderão ser trilhados caminhos para o aperfeiçoamento dos algoritmos em conformidade com os direitos e liberdades fundamentais de todos os cidadãos, que servirá de abertura para uma nova e promissora fase para a governança.

\section{REFERÊNCIAS}

ANGWIN, Julia et. al. Machine Bias: There's software used across the country to predict future criminals. And it's biased against blacks. 23 maio 2016. Disponível em: http://www.propublica.org/article/machine-bias-risk-assessments-in-criminal-sentencing.

Acesso em: 04 abr. 2021.

BAUMAN, Zygmunt. Capitalismo parasitário: e outros temas contemporâneos. Zygmunt Bauman e Tim May. Rio de Janeiro: Zahar, 2010. 
BAUMAN, Zygmunt. Vigilância líquida. Diálogos com David Lyon. Rio de Janeiro: Zahar, 2014.

BIGO, D. Security, exception, ban and surveillance. In: Theorizing Surveillance: the panopticon and beyond. Lyon, D. (ed.). Willan Publishing. Portland: Willan Publishing, 2006.

BOND, Michaelle. Government Is Using Algorithms - Is It Assessing Bias? Government Technology. 10 dez. 2018. Disponível em: http://www.govtech.com/dc/Government-is-UsingAlgorithms-Are-They-Assessing-Bias.html. Acesso em: 05 abr. 2021.

BURACK, Justin. Addressing Algorithmic Discrimination in the European Union. A Path for Europe. Novembro, 24, 2020. Disponível em: http://pathforeurope.eu/addressingalgorithmic-discrimination-in-the-european-union/. Acesso em: 21 mar. 2021.

CEREIJIDO, Fanny Blanck. O olhar sobre o estrangeiro: The gaze on the foreigner. Ide (São Paulo), São Paulo, v. 31, n. 47, p. 61-65, dez. 2008. Disponível em <http://pepsic.bvsalud.org/scielo.php?script=sci_arttext\&pid=S010131062008000200010\&lng=pt\&nrm=iso >. acessos em 21 mar. 2021.

CORBETT-DAVIES, Sam et.al. A computer program used for bail and sentencing decisions was labeled biased against blacks. It's actually not that clear. The Washington Post, Monkey Cage, 17 out. 2016. Disponível em: http://www.washingtonpost.com/news/monkeycage/wp/2016/10/17/can-an-algorithm-be-racist-our-analysis-is-more-cautious-thanpropublicas/?noredirect=on. Acesso em: 04 abr. 2021.

DE GENOVA, Nicholas. Spectacles of migrant 'illegality': the scene of exclusion, the obscene of inclusion. Ethnic and Racial Studies, 36: 7, 1180-1198, DOI: 10.1080/01419870.2013.783710. Acesso em: 04 abr. 2021.

DHASARATHY, Anusha; JAIN, Sahil; KHAN, Naufal. When governments turn to AI: Algorithms, trade-offs, and trust. 19 out. 2020. Disponível em: http://www.mckinsey.com/industries/public-and-social-sector/our-insights/whengovernments-turn-to-ai-algorithms-trade-offs-and-trust\#. Acesso em: 04 abr. 2021.

DONNELLY, Drew. An Introduction to the China Social Credit System. New Horizons. 18 mar. 2021. Disponível em: http://nhglobalpartners.com/china-social-credit-systemexplained/. Acesso em: 02 abr. 2021.

DUTCH Court Rules Secret Welfare Algorithm Violates Human Rights. Electronic Privacy Information Center. Washington, Fevereiro, 5, 2020. Disponível em: http://epic.org/2020/02/dutch-court-rules-secret-welfa.html. Acesso em: 21 mar. 2021.

ETHICS \& Algorithms Toolkit. Creative Commons Attribution 4.0 International. Disponível em: http://ethicstoolkit.ai/. Acesso em: 04 abr. 2021.

FLORES, Anthony W.; LOWENKAMP, Christopher T.; BECHTEL, Kristin. False Positives, False Negatives, and False Analyses: A Rejoinder to "Machine Bias: There's Software 
Used Across the Country to Predict Future Criminals. And it's Biased Against Blacks." Disponível em: http://www.crj.org/assets/2017/07/9_Machine_bias_rejoinder.pdf. Acesso em: 04 abr. 2021.

FREUD. Sigmund. (1919). O infamiliar [Das Unheimliche]. Edição comemorativa bilíngue (1919-2019). Tradução Ernani Chaves, Rogério Freitas e Pedro Heliodo Tavares. Editora Autêntica: 2019.

HOLDER JR., Eric H. Attorney General Eric Holder Speaks at the National Association of Criminal Defense Lawyers 57th Annual Meeting and 13th State Criminal Justice Network Conference. The United States Department of Justice. Philadelphia, PA, August 1, 2014. Disponível em: http://www.justice.gov/opa/speech/attorney-general-eric-holder-speaksnational-association-criminal-defense-lawyers-57th. Acesso em: 04 abr. 2021.

KLEINBERG, Jon; MUllainathan, Sendhil; RAGHAVAN, Manish. Compensações inerentes na determinação justa das pontuações de risco. Cornell University, 19 set. 2016, revisado em 17 nov. 2016. Disponível em: http://arxiv.org/abs/1609.05807. Acesso em: 04 abr. 2021.

KRANZBERG, Melvin. Technology and History: "Kranzberg's laws". Bull. Sci. Tech. Soc., Vol. 15, N. 1, pp. 5-13, 1 fev. 1995, STS Press. http://doi.org/10.1177/027046769501500104. Disponível em: http://journals.sagepub.com/doi/abs/10.1177/027046769501500104. Acesso em: 04 abr. 2021.

LEMES, Marcelle Martins. Inteligência artificial, algoritmos e policiamento preditivo no poder público federal brasileiro. 2019. Trabalho de Conclusão de Curso (Bacharelado em Direito), Universidade de Brasília, Brasília, 2019. Disponível em: http://bdm.unb.br/handle/10483/24565. Acesso em: 02 abr. 2021.

MENEZES NETO, Elias Jacob de. Vigilância ou surveillance? Proposta para começar a compreender corretamente este fenômeno. Revista dos Tribunais, v. 939, p. 159-182, jan. 2014. Disponível em: http://dspace.almg.gov.br/handle/11037/21500. Acesso em: 03 abr. 2021.

MORAIS, José Luis Bolzan de. O Estado de Direito "confrontado" pela "revolução da internet"! Revista Eletrônica do Curso de Direito da UFSM, v. 13, n. 3, pp. 876-903, 2018. Disponível em: http://periodicos.ufsm.br/revistadireito/article/view/33021. Acesso em: 03 abr. 2021.

OPEN Data Strategic Plan. Cambridge open data. 1 abr. 2019. Disponível em: http://data.cambridgema.gov/General-Government/Open-Data-Strategic-Plan/w7ax-fa5u.

Acesso em: 05 abr. 2021.

SCHMITT, Carl. O conceito do político. Petrópolis: Vozes, 1992.

SNIRCEK, Nick. Platform capitalism. Cambridge: Polity Press, 2017. Resenha de: SILVA NETO, Victo. Revista Brasileira de Inovação, 18(2):449-454, Unicamp. DOI: 
10.20396/rbi.v18i2.8654960.

Disponível

em: http://periodicos.sbu.unicamp.br/ojs/index.php/rbi/article/view/8654960/21737. Acesso em: 04 abr. 2021.

STATE v. Loomis. Wisconsin Supreme Court Requires Warning Before Use of Algorithmic Risk Assessments in Sentencing. Harvard law review. Criminal law. 10 mar. 2017. Disponível em: http://harvardlawreview.org/2017/03/state-v-loomis/. Acesso em: 04 abr. 2021.

TASHEA, Jason. Courts Are Using AI to Sentence Criminals. That Must Stop Now. Opinion: Courts should pause the use of algorithms for criminal sentencing. Wired. 17 abr. 2017. Disponível em: http://www.wired.com/2017/04/courts-using-ai-sentence-criminals-must-stopnow/. Acesso em: 04 abr. 2021.

THIESEN, Icléia; SANTANA, Marco Aurélio. Do exame à identificação ou do panóptico ao banóptico: memória e representações. Identidades. XIII Encontro de História Anpuh Rio. 2008. Disponível em: http://encontro2008.rj.anpuh.org/resources/content/anais/1212615086_ARQUIVO_Thiesen\& Santanaanpuhriofinaljunho\%5B1\%5D.pdf. Acesso em: 04 abr. 2021. 